\title{
Links between Biomass of (Cremastra Appendiculata) Stems Cuticle and Elevation by Big Data of Long-Time Wild Investigation in Mei County
}

\author{
Bing-Hua Liao \\ The Key Laboratory of Ecological Restoration in Hilly Areas, Forestry Department of Henan Province, Institute of \\ chemistry and environmental engineering, Ping-ding-shan University, Ping-ding-shan City, 467000, China \\ Institute of life and science, Henan University, Kai-feng City, He-nan Province, 475004, China \\ Email: $\underline{\text { lbh@henu.edu.cn }}$
}

Article History

Received: November 5, 2020

Revised: December 6, 2020

Accepted: December 9, 2020

Published: December 12, 2020

\begin{abstract}
(Cremastra appendiculata) of treating lumbago and arthritis not only is a vital medicinal material plant, but also it is a widely distributed wide plant species. This plant species is widely distributed elevation from $500 \mathrm{~m}$ to $3100 \mathrm{~m}$ in forest landscapes and vegetation ecosystems in Mei County of China. However, understanding dynamics of biomass of stems cuticle of this species is difficult along elevation. This research explained that the links between biomass of stems cuticle of this species and elevation is the significant positive correlation from $500 \mathrm{~m}$ to $1500 \mathrm{~m}(\mathrm{P}<0.01)$ as well as the links between biomass of stems cuticle of this species and elevation are the significant negative correlation from $1500 \mathrm{~m}$ to $3100 \mathrm{~m}(\mathrm{P}<0.01)$. This study provides six ecosystem types and a series of areas ecological adaptation for finding new medicinal species. Therefore, this study has vital theoretical and practical significance for medicinal plant protection along elevation.
\end{abstract}

Keywords: Biomass of stems cuticle; Elevation; Correlation; Areas ecological adaptation; Medicinal species.

\section{Introduction}

More and more research has assessed the correlation among biomass (average height, numbers, biodiversity, structure) of plant species and elevation from biomass (average height, numbers. biodiversity, structure) of the medicinal plant perspective (Table 1) [1-11], for better future of human health (ecosystems) [6-14]. However, medicinal species with typical history spanning over 1500 years, as well as areas ecological adaptation of a lot of fresh biomass weight of medical species are unknown, and cognitive ecological theory of the links between fresh biomass weight of medicinal species and elevation can be unknown along elevation and environments [12-19].

Thus, understanding these medical values of medicinal plant spices, as well as the links between of fresh biomass weight of medical species of different areas ecological adaptation and elevation is a vital rule along elevation at the spatial-temporal-environmental-disturbance scales (STEDS).

(Cremastra appendiculata) not only is vital medicinal material of treating lumbago and arthritis, but also is widely distributed wide specie in Mei County of China. This specie is belonging to Cremastra genus of Orchidaceae families of Monocotyledoneae in Angiospermae. Understanding dynamics of biomass of stems cuticle of this species is unknown,however. Indeed, our research not only explained that there are links between biomass of stems cuticle of this species and elevation, but also explained that this species is key plant species of treating lumbago and arthritis.

Therefore, there are vital rules that the links between biomass of stems cuticle of (Cremastra appendiculata) and elevation at STEDS in the vegetation landscapes of Mei County of China.

Table-1. Links between medicinal plant structure number (biomass, height) and elevation

\begin{tabular}{l|l}
\hline Links between medicinal plant structure number (biomass, height) and elevation & Authors \\
\hline Links between elevation environments and numbers of plant species at STEDS. & {$[1]$.} \\
\hline Links between biomass of medicinal herb and elevation in wetland landscape. & {$[2]$.} \\
\hline Links between plant functional number and elevation in forest landscape. & {$[3]$.} \\
\hline Links between plant functional number and elevation in near-natural forests. & {$[4]$.} \\
\hline Links between herbs number and disturbance of different elevation in wetland. & {$[5]$} \\
\hline Links between number of medicinal tree species and elevation in forestation. & {$[6]$.} \\
\hline Links between number of medicinal tree trunk volume and elevation at STEDS. & {$[8]$.} \\
\hline Links between height of medicinal tree and elevation in the natural landscape. & {$[7]$.} \\
\hline Links between number of tree community crown volume and elevation in forest. & {$[9]$.} \\
\hline Links between number of tree individual specie's crown volume and elevation. & {$[10]$.} \\
\hline Links between herbs number and different disturbance of different elevation. & {$[11]$.} \\
\hline
\end{tabular}




\section{Typical Environmental Condition, Situation of Typical Vegetation and Methods of Research}

Typical area is local in three zones: firstly, evergreen vegetation of north subtropical zone; secondly, evergreen and deciduous coniferous and broad-leaved mixed forest of north subtropical and warm temperate transition; thirdly, deciduous vegetation of warm temperate zone in Earth. Thus, our research area is local in evergreen and deciduous coniferous and broad-leaved mixed forest in north subtropical and warm temperate transition in Mei County of China (Figure 1).

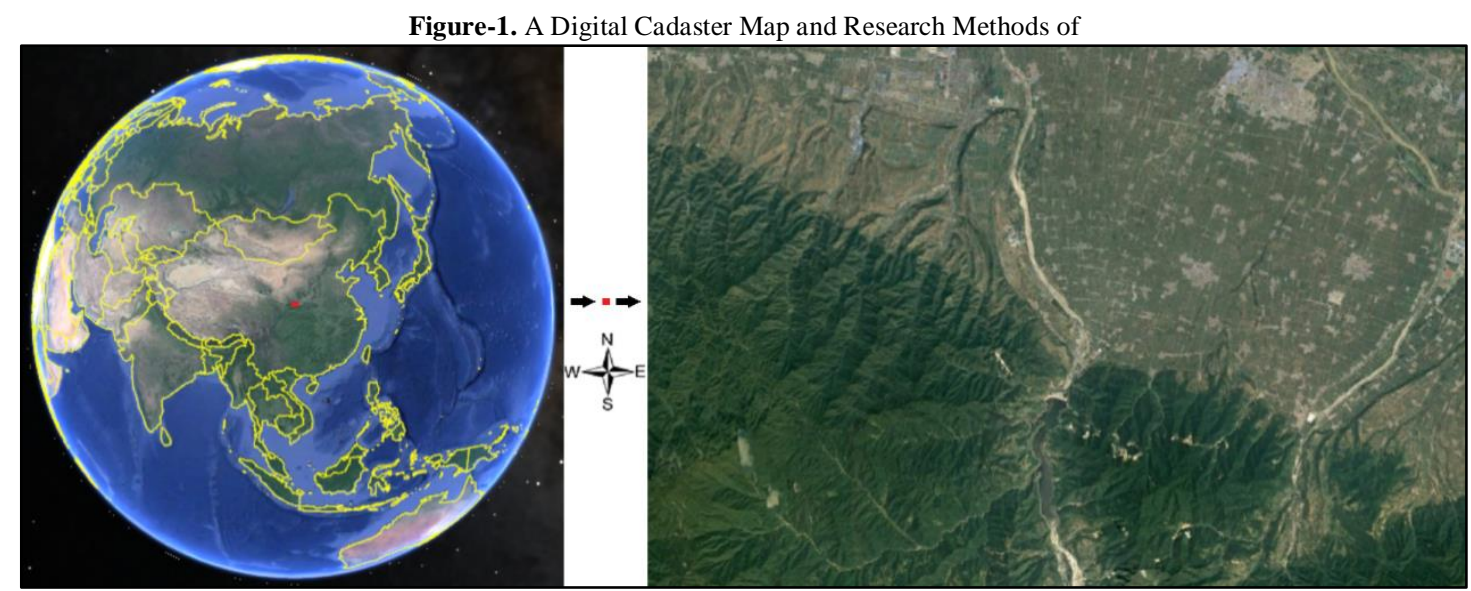

\subsection{Typical Location in Mei County of China of Earth}

There is a long-time investigation of the correlations among biomass of stems cuticle of medicinal plant species and elevation from 2005 to 2019. Investigation of "big data" included that biomass of stems cuticle or other index of medicinal plant species along different elevation and environmental gradient by previous our researches [2-16].

Thus, there is the links between biomass of (Cremastra appendiculata) stems cuticle and elevation, as well as there is a series of (good, better, best) natural landscapes areas ecological adaptation of biomass of (Cremastra appendiculata) stems cuticle by the "big data" of the ecological investigation, qualitative analysis, quantitative statistics, human cognitive ecological linguistic rules, theories, methods and ways along elevation and environmental gradient [3-23].

\section{Results and Analysis}

Based on "big data" of plant investigation, this species is a widely distributed wide species along elevation from $500 \mathrm{~m}$ to $3100 \mathrm{~m}$. (Cremastra appendiculata) is a widely distributed along the different elevation from $500 \mathrm{~m}$ to $3100 \mathrm{~m}$ in Mei County of China. However, understanding the elevation effect on the links between biomass of stems cuticle of this plant species and elevation is very difficult, because elevation effect on biomass of stems cuticle of medicinal species [2-26].

Using the dynamics of "big data" investigation, this research suggested there are four rules:

Firstly, this research suggested that there is not only the increasing of fresh biomass weight of (Cremastra appendiculata) with increasing of elevation from $500 \mathrm{~m}$ to $1500 \mathrm{~m}$, as well as there are but also decreasing of biomass of stems cuticle of (Cremastra appendiculata) with increasing of elevation from $1500 \mathrm{~m}$ to $3100 \mathrm{~m}$ at the STEDS in Mei County of China (Figure 2).

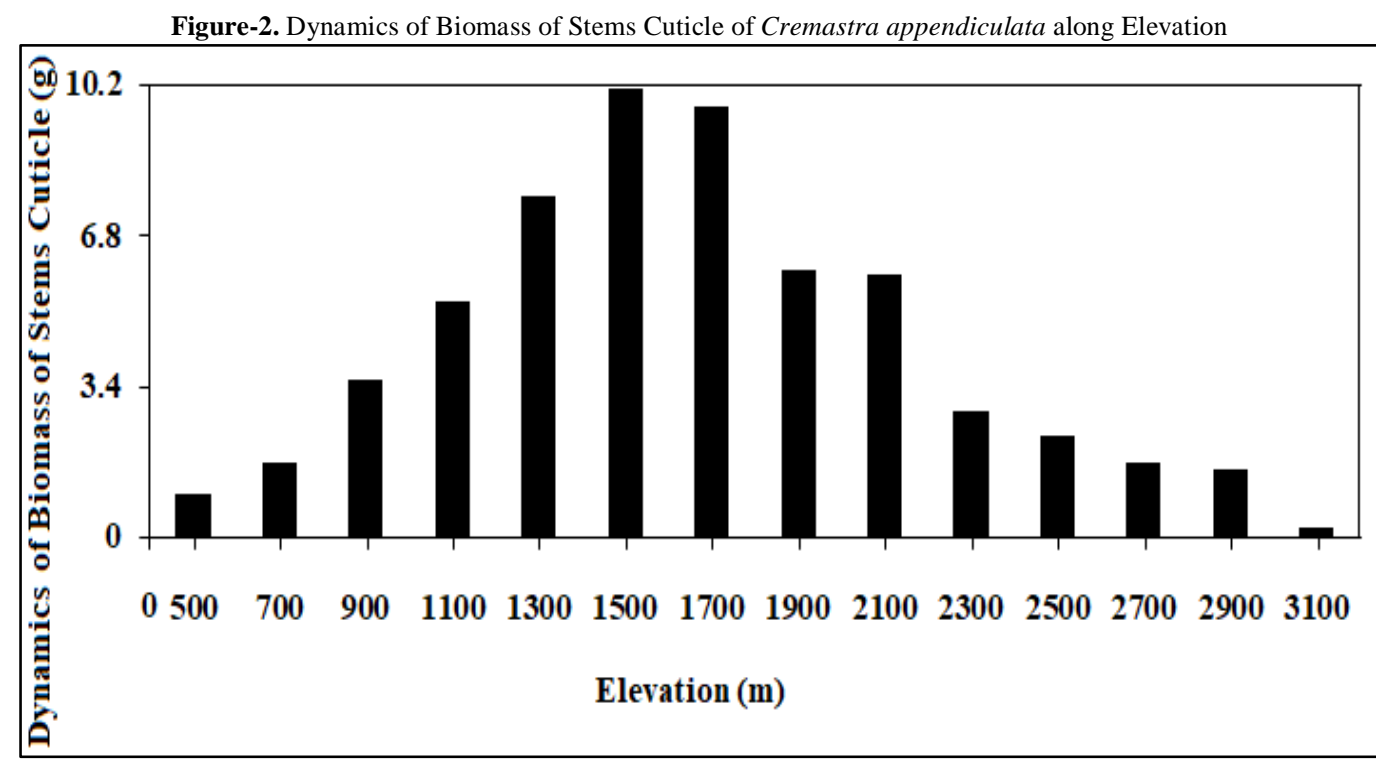


Secondly, this study explained that there is the significant positive correlation between biomass of stems cuticle of (Cremastra appendiculata) and elevation from $500 \mathrm{~m}$ to $1500 \mathrm{~m}(P<0.01)$, as well as there is the significant negative correlation between biomass of stems cuticle of (Cremastra appendiculata) and elevation from $1500 \mathrm{~m}$ to $3100 \mathrm{~m}$ in Mei County $(P<0.01)$ (Table 2).

Table-2. Correlation between Biomass of Stems Cuticle of this Plant Species and Elevation

\begin{tabular}{l|l|l}
\hline Elevation $(\mathbf{m})$ & Elevation From $500 \mathrm{~m}$ to $1500 \mathrm{~m}$ & Elevation From 150m to 3100m \\
\hline Biomass of Stems cuticle & $0.988^{* *}$ & $-0.967 * *$ \\
\hline Note: $* *, P<0.01$.
\end{tabular}

Thirdly, this research provides a good areas ecological adaptation of (Cremastra appendiculata) from 500m to 3100 in Mei County in China. Meanwhile, this research proposed that there is not only the better area ecological adaptation of (Cremastra appendiculata) from $1000 \mathrm{~m}$ to $2000 \mathrm{~m}$, there is but also the best areas ecological adaptation of (Cremastra appendiculata) from $1300 \mathrm{~m}$ to $1700 \mathrm{~m}$; because there are results that there are not only dynamics of different air environmental factors, there are but also dynamics of different soil environmental factors from $500 \mathrm{~m}$ to $3100 \mathrm{~m}$ by the dynamics of biomass of stems cuticle of this species in Mei County at STEDS (Figure 2).

Fourthly, this research proposed that medicinal plant species (Cremastra appendiculata) is local in the six typical ecosystem types (forestation ecosystem, mixed ecosystem between forestation and grassland, mixed ecosystem between forestation and wetland, mixed ecosystem between forestation and river, mixed ecosystem between forest and urban, mixed ecosystem between forestation and rural settlement) by the "big data" of biomass of stems cuticle of medicinal plant species investing along elevation, because there may be results that there are not only dynamics of air environments, there are but also dynamics of soil environmental factors from $500 \mathrm{~m}$ to $3100 \mathrm{~m}$ along environmental factors of different elevation at STEDS in Mei County of China.

Indeed, better regional regulators and local government need better planning and regulation a lot of medicinal plant management sustainability of ecosystems by the researches on biomass of stems cuticle along elevation and environments with dynamics of biodiversity in the global, local, regional natural ecosystem types with the ways "big data" investigation, quantitative statistics, scientific analysis for better future of vegetation ecosystems and human health at the STEDS [27-40].

Thus, this research found a series of typical (good, better, best) areas ecological adaptation of (Cremastra appendiculata) of treating lumbago and arthritis along elevation gradient, as well as there is the links between fresh biomass weight of this medical species and elevation gradient.

\section{Conclusion and Discussion}

Understanding dynamics of medicinal plant species is very difficult [1-8, 41-47]. This research suggested three rules between stems cuticle biomass of (Cremastra appendiculata) and elevation:

1. This research suggested that there is increasing of biomass of stems cuticle of (Cremastra appendiculata) with increasing of elevation from $500 \mathrm{~m}$ to $1500 \mathrm{~m}$, as well as there is decreasing of biomass of stems cuticle of (Cremastra appendiculata) with increasing of elevation from $1500 \mathrm{~m}$ to $3100 \mathrm{~m}$ (Figure 2). There is the significant positive correlation between biomass of stems cuticle of (Cremastra appendiculata) and elevation from $500 \mathrm{~m}$ to $1500 \mathrm{~m}(P<0.01)$ as well as there is the significant negative correlation between biomass of stems cuticle of (Cremastra appendiculata) and elevation from $1500 \mathrm{~m}$ to $3100 \mathrm{~m}$ along elevation in Mei County of China $(P<0.01)$ (Table 2).

2. This research provides six vegetation types (forestation vegetation, mixed vegetation between forestation and grassland, mixed vegetation between forestation and wetland, mixed vegetation between forestation and river, mixed vegetation between forest and urban, mixed vegetation between forestation and rural settlement), as well as there is a series of areas ecological adaptation (a good areas ecological adaptation of Cremastra appendiculata from $500 \mathrm{~m}$ to 3100 , the better area ecological adaptation of Cremastra appendiculata from $1000 \mathrm{~m}$ to $2000 \mathrm{~m}$, the best areas ecological adaptation of Cremastra appendiculata from $1300 \mathrm{~m}$ to $1700 \mathrm{~m}$ ) for finding (Cremastra appendiculata) by dynamics of biomass of stems cuticle of (Cremastra appendiculata) at STEDS.

3. (Cremastra appendiculata) not only is a vital medicinal material of treating lumbago and arthritis, but also it is belonging to Cremastra genus of Orchidaceae families of Monocotyledoneae in Angiospermae, as well as it is widely distributed wide specie by the "big data" investigation of biomass of stems cuticle of (Cremastra appendiculata) in Mei County of China at STEDS.

Therefore, this research has a vital theoretical and practical significance for the reasonable protection of (Cremastra appendiculata) along different elevation gradient in the different ecosystems, because this plant species not only is an important widely distributed wide medicinal material pant by treating lumbago and arthritis, but also there are three rules by the links between biomass of stems cuticle of (Cremastra appendiculata) and elevation in Mei County of China.

\section{Acknowledgement}

This work was supported by A Grade of Key Disciplines of Environmental Science Foundation, B Grade of Key Disciplines of Mistrials Science of Ping-Ding-shan University in China; Science and Technology Department of He'nan Province Foundation (KJT-17202310242; 092102110165); Subprojects by Intergovernmental Platform on Biodiversity and Ecosystem Services (IPBES); and better ideas of researchers of "1st Biotechnology World 
Congress” in 2011, "2st Biotechnology World Congress” in 2012, "3st Biotechnology World Congress” in 2013 is appreciated.

\section{References}

[1] Liao and Wang, X. H., 2010. " Plant functional group classifications and a generalized hierarchical framework of plant functional traits." African Journal of Biotechnology, vol. 9, pp. 9208-9213.

[2] Liao, Ding, S. Y., and Liang, G. F., 2011a. "Dynamics of plant functional groups composition along environmental gradients in the typical area of Yi-Luo River watershed." African Journal of Biotechnology, vol. 10, pp. 14485- 14492.

[3] Liao, Ding, S. Y., and Hu, N., 2011b. "Dynamics of environmental gradients on plant functional groups composition on the northern slope of the Fu-Niu Mountain Nature Reserve." African Journal of Biotechnology, vol. 10, pp. 18939-18947.

[4] Liao, Liu, Q. F., and Lu, D., 2014. "Dynamics of environmental gradients on plant functional groups composition species in near-natural community ecological restoration on the southern slope of the Fu-Niu Mountain Nature Reserve." Journal of Science, vol. 4, pp. 306-312.

[5] Chen, H. S., Liao, B. H., and Hang, C. Z., 2019. "Research on risk assessment and early warning mechanism of agricultural non-point source pollution in Bai-gui Lake watershed by GIS." International Journal of Pharmacognosy and Pharmaceutical Sciences, vol. 1, pp. 25-29.

[6] Liao, Liu, M., and Huang, C. Z., 2019a. "Dynamics of(sophora japonica)community's tree individual number along elevation gradient in ye county." International Journal of Pharmacognosy and Pharmaceutical Sciences, vol. 1, pp. 1-4.

[7] Liao, Liu, Y. P., and Zuo, H., 2019c. "Dynamics of 18 (Sophora japonica) Tree community's total trunk volume along elevation gradient in ye county." International Journal of Current Advanced Research, vol. 8, pp. 19063-19066.

[8] Liao, Liu, Y. P., and Zuo, H., 2019b. "Elevation dynamics of (Sophora japonica) community's height in ye county." International Journal of Research Pharmaceutical and Nano Sciences, vol. 8, pp. 48-54.

[9] Liao and Liu, Y. P., 2019d. "Dynamics crown volume of 18 (Sophora japonica) tree communities along elevation gradient in ye county." Open Journal of Ecology, vol. 9, pp. 209 -215.

[10] Liao, Liu, Y. P., and Zuo, H., 2019e. "Dynamics of 18 (Sophora japonica) tree individual specie's crown volume along elevation gradient in ye county." International Journal of Research Pharmaceutical and Nano Sciences, vol. 8, pp. 62-68.

[11] Liao, 2014b. "A new model of dynamic of plant diversity in changing farmlands, implications for the management of plant biodiversity along differential environmental gradient in the spring." African Journal of Environmental Science and Technology, vol. 8, pp. 171-177.

[12] Zhu, D. M. and Liao, B. H., 2015. "A dynamical system of human cognitive linguistic theory in learning and teaching of the typical university in Henan Province." International Journal of Pharmacy and Therapeutics, vol. 6, pp. 4-6.

[13] Yang, Y. and Sun, M., 2020. "Germplasm resources and genetic breeding of Paeonia: A systematic review." Horticulture Research, vol. 7, pp. 1-19.

[14] Jin, D. and Dai, K. P., 2020. "Secondary metabolites profiled in cannabis inflorescences, leaves, stem barks, and roots for medicinal purposes." Scientific Reports, vol. 10, pp. 1-14.

[15] Kozuharova, E. and Matkowski, A., 2017. "Amorpha fruticosa - a noxious invasive alien plant in Europe or a medicinal plant against metabolic disease?" Front Pharmacol, vol. 8, p. 333.

[16] Giovannini, P., Howes, M. J., and Edwards, S. E., 2016. "Medicinal plants used in the traditional management of diabetes and its sequelae in Central America: A review." J. Ethnopharmacol., vol. 184, pp. 58-71.

[17] Szopa, A., Klimek-Szczykutowicz, M., and Kokotkiewicz, A., 2019. "Phenolic acid and flavonoid production in agar,agitated and bioreactor-grown microshoot cultures of Schisandra Chinensis cv. Sadova No.1 - a valuable medicinal plant." J. Biotechnol., vol. 305, pp. 61-70.

[18] Mesfin, F., Demissew, S., and Teklehaymanot, T., 2009. "An ethnobotanical study of medicinal plants in Wonago Woreda, SNNPR, Ethiopia." J. Ethnobiol Ethnomed., vol. 5, p. 28.

[19] Elkins, A. C., Deseo, M. A., and Rochfort, S., 2019. "Development of a validated method for the qualitative and quantitative analysis of cannabinoids in plant biomass and medicinal cannabis resin extracts obtained by super-critical fluid extraction." J. Chromatogr B. Analyt Technol. Biomed Life Sci., vol. 109, pp. 76-83.

[20] Baque, M. A., Moh, S. H., and Lee, E. J., 2012. "Production of biomass and useful compounds from adventitious roots of high-value added medicinal plants using bioreactor." Biotechnol. Adv., vol. 30, pp. 1255-1267.

[21] Saeed, S., Ali, H., and Khan, T., 2017. "Impacts of methyl jasmonate and phenyl acetic acid on biomass accumulation and antioxidant potential in adventitious roots of Ajuga bracteosa Wall ex Benth., a high valued endangered medicinal plant." Physiol. Mol. Biol. Plants., vol. 23, pp. 229-237.

[22] Prasad, R., Kamal, S., and Sharma, P. K., 2013. "Root endophyte Piriformospora indica DSM 11827 alters plant morphology, enhances biomass and antioxidant activity of medicinal plant Bacopa monniera." $J$. Basic Microbiol., vol. 53, pp. 1016-1024.

[23] Fuentes, P., Zhou, F., and Erban, A., 2016. "A new synthetic biology approach allows transfer of an entire metabolic pathway from a medicinal plant to a biomass crop." Elife., vol. 5, pp. e1360-1364. 
[24] Rukh, G. and Ahmad, N., 2019. "Photodependent somatic embryogenesis from non-embryogenic calli and its polyphenolics content in high-valued medicinal plant of Ajuga bracteosa." J. Photochem Photobiol. B., vol. 190, pp. 59-65.

[25] Das, Kamal, S., and Shakil, N. A., 2012. "The root endophyte fungus Piriformospora indica leads to early flowering, higher biomass and altered secondary metabolites of the medicinal plant, Coleus forskohlii." Plant Signal Behav., vol. 7, pp. 103-112.

[26] Schafhauser, T., Jahn, L., and Kirchner, N., 2019. "Antitumor astins originate from the fungal endophyte Cyanodermella asteris living within the medicinal plant Aster tataricus." Proc Natl Acad Sci USA., vol. 116, pp. 26909-26917.

[27] Singh, S. P. and Gaur, R., 2016. "Evaluation of antagonistic and plant growth promoting activities of chitinolytic endophytic actinomycetes associated with medicinal plants against Sclerotium rolfsii in chickpea." J. Appl. Microbiol., vol. 121, pp. 506-518.

[28] Das, Dang, R., Shivananda, T. N., and Sur, P., 2005. "Interaction between phosphorus and zinc on the biomass yield and yield attributes of the medicinal plant stevia (Stevia rebaudiana)." Scientific World Journal, vol. 5, pp. 390-395.

[29] Zubek, S., Mielcarek, S., and Turnau, K., 2012. "Hypericin and pseudohypericin concentrations of a valuable medicinal plant Hypericum perforatum L. are enhanced by arbuscular mycorrhizal fungi." Mycorrhiza., vol. 22, pp. 149-156.

[30] Takshak, S. and Agrawal, S. B., 2015. "Defence strategies adopted by the medicinal plant Coleus forskohlii against supplemental ultraviolet-B radiation: Augmentation of secondary metabolites and antioxidants." Plant. Physiol. Biochem., vol. 97, pp. 124-138.

[31] Larsen, H. O., 2002. "Commercial medicinal plant extraction in the hills of Nepal: local management system and ecological sustainability." Environ Manage., vol. 29, pp. 88-101.

[32] Bojić, M., Maleš, Ž., and Antolić, A., 2019. "Antithrombotic activity of flavonoids and polyphenols rich plant species." Acta Pharm., vol. 69, pp. 483-495.

[33] Maleš, Ž. and Drvar, D. L., 2019. "Application of medicinal plants in several dermatovenerological entities." Acta Pharm., vol. 69, pp. 525-531.

[34] Wyk, B. E. V., 2015. "A review of commercially important African medicinal plants." J. Ethnopharmacol., vol. 176, pp. 118-134.

[35] Ali, H., Khan, M. A., and Kayani, W. K., 2019. "Production of biomass and medicinal metabolites through adventitious roots in Ajuga bracteosa under different spectral lights." J. Photochem. Photobiol. B., vol. 193, pp. 109-117.

[36] Song, H. and Payne, S., 2009. "Spatiotemporal modulation of biodiversity in a synthetic chemicalmediated ecosystem." Nature Chemical Biology, vol. 5, pp. 929-935.

[37] Opgenoorth, L., Hotes, S., and Mooney, H., 2014. "IPEPS: Biodiversity panel should play by rules." Nature, vol. 506, p. 159.

[38] Cardinate, B. J. and Duffy, J. E., 2012. "Corrigendum: Biodiversity loss and its impact on humanity." Nature, vol. 489, p. 326.

[39] Mooers, A. O., 2014. "Biodiversity: Supply and demand." Nature, vol. 509, pp. 171-172.

[40] Liao, M. G. M. and Ekins, P., 2019. "Limits to agricultural land for retaining acceptable levels of local biodiversity." Nature Sustainability, vol. 2, pp. 491-498.

[41] Oehri, J. and Schmid, B., 2020. "Terrestrial land-cover type richness is positively linked to landscape-level functioning." Nature Communications, vol. 11, pp. 1-10.

[42] Hanski, I. and Schulz, T., 2017. "Ecological and genetic basis of metapopulation persistence of the Glanville fritillary butterfly in fragmented landscapes." Nature Communications, vol. 8, pp. 1-11.

[43] Marlier, M. E. and DeFries, R. S., 2012. "El Niño and health risks from landscape fire emissions in southeast Asia." Nature Climate Chang, vol. 3, pp. 131-136.

[44] Clough, Y. and Krishna, V., 2016. "Land-use choices follow profitability at the expense of ecological functions in Indonesian smallholder landscapes." Nature Communications, vol. 7, pp. 1-12.

[45] Cámara-Leret, R. and Dennehy, Z., 2019. "Information gaps in indigenous and local knowledge for sciencepolicy assessments." Nature Sustainability, vol. 2, pp. 736-741.

[46] Ji, B. W. and Sheth, R. U., 2019. "Quantifying spatiotemporal variability and noise in absolute microbiota abundances using replicate sampling." Nature Methods, vol. 16, pp. 731-736.

[47] Battin, T. J. and Sloan, W. T., 2007. "Microbial landscapes: New paths to biofilm research." Nature Reviews Microbiology, vol. 5, pp. 76-81. 